\title{
RISK REDUCTION IN TRANSPORT SYSTEM IN EMERGENCY CONDITIONS: A FRAMEWORK FOR EVACUATION PLANNING
}

\author{
CORRADO RINDONE \& PAOLA PANUCCIO \\ Dipartimento di ingegneria dell'Informazione, delle Infrastrutture e dell'Energia Sostenibile, \\ Università degli studi Mediterranea di Reggio Calabria, Italy
}

\begin{abstract}
Emergency planning is part of the broader disaster management cycle that, at the international level, is identified with the following keywords: prevention; mitigation or prevention; preparedness; response; recovery. The paper focuses on preparedness and in particular on the planning process for ordinary and extraordinary conditions. The specific focus is on the evacuation planning process. In the last years, the United Nations (UN) and European Commission (EC) dedicated a great effort to pursue disaster risk reduction. At aiming this goal, $\mathrm{UN}$ and $\mathrm{EC}$ promote frameworks to orient the urban emergency planning process. Despite the European addresses, there is no uniformity of approaches for evacuation planning adopted by the Countries. This paper proposes a framework for evacuation planning at the urban scale, with a focus on passenger mobility. The proposed framework integrates theories produced by science, rules produced by laws and implementation in real cases. Planning, training, exercises and evaluation tools are the main elements of the framework that work to reduce risk. Some elements of the Italy case study will be presented.

Keywords: emergency, risk, exposure, evacuation, urban planning.
\end{abstract}

\section{INTRODUCTION}

Emergency planning is part of the broader disaster management cycle that, at the international level, is identified with the following keywords: prevention, including the needed activities to avoid accidents; mitigation or protection, including activities to protect users by emergency's effects; preparation, including activities to increase the capability to cope with a disastrous event; response, including activities carried out immediately before and/or during and after the occurrence of a disastrous event; recovery including the activities necessary to return to ordinary conditions [1].

The Sendai Framework for Disaster Risk Reduction 2015-2030 is the adopted document by member states of the United Nations to pursue disaster risk reduction at global level. The framework indicates four priorities for action concerning: (i) understanding disaster risk; (ii) Strengthening disaster risk governance to manage disaster risk; (iii) investing in disaster reduction for resilience; (iv) enhancing disaster preparedness. The priorities are translated into seven objectives which correspond to specific quantitative targets [2].

European Commission supports Sendai Framework with a specific action plan. This integrates the EU Civil Protection Mechanism (EUCPM), adopted since 2001 to promote the cooperation among national authorities for civil protection [3].

Emergency planning [4], [5] is strictly related to territorial planning that is possible to classify on (Fig. 1):

- planning for ordinary conditions [6], [7] where decisions concern the asset of a territory (urban, region, etc.) in terms of land uses [8] and quantitative standard allocation of infrastructures and services [9], [10] which respond to territorial needs of people, business and decision makers in usual situations [11], [12]; 
- planning for extraordinary conditions [13] where decisions concern external constraints for respecting rules [14] or specific regulations defined for risk reduction [15].
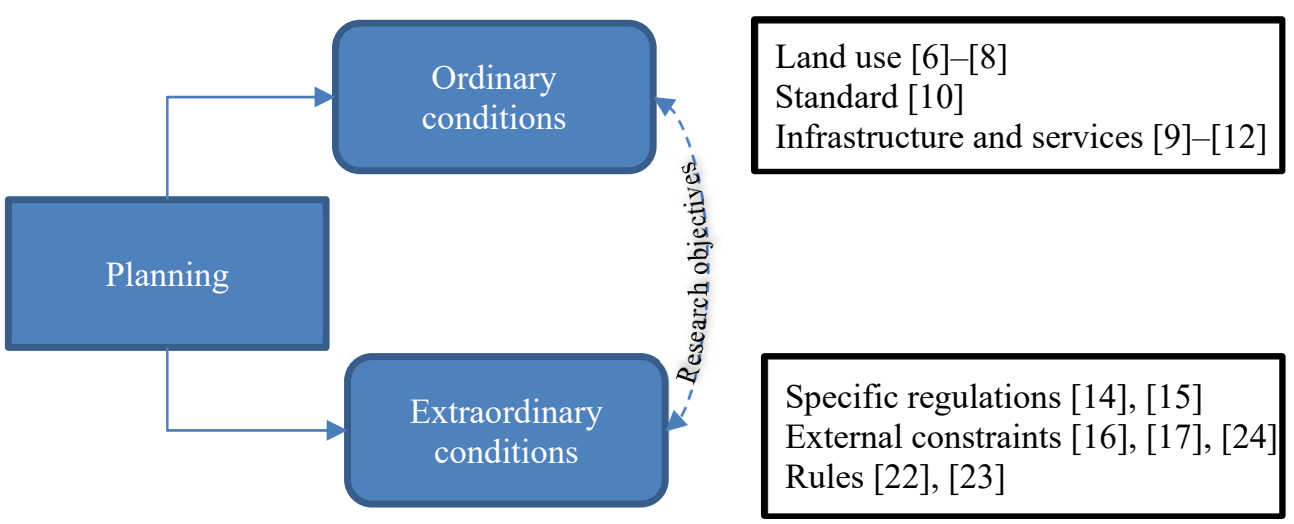

Figure 1: Classification of planning.

In literature and in real applications the two classes of planning are not interrelated [16], [17]. Despite UN or EU indications, there is no integration among territorial decisions that could produce effects for ordinary and/or extraordinary conditions. The present research has the objective to investigate the interrelation between the two forms of planning. The specific focus is on evacuation planning that has to be activated to reduce risk and in particular the exposure component. In particular, the paper proposes a framework for evacuation planning. The framework defines an integrated planning process that includes planned actions concerning training, experimentation and evaluation tools to evaluate progressive improvements and then corrective actions [18]. The framework is defined according to smart city concept where more urban systems are planned and managed in an integrated way, as system of systems where people and business needs are at the center of the decisions.

The paper is connected with other papers focused on risk reduction in the transport system. Planning needs of the support of Transport System Models (TSM) and in particular: models for network design problem [18]; transport demand analysis [19]; transport supply analysis [20]; integration of TSM in Decision Support System (DSS) [21].

After this introduction, the paper has four sections. Section 2 illustrates the main elements of the proposed emergency planning process. Section 3 illustrated the proposed framework for evacuation planning. Section 4 reports the main results of the Italian case study. The final section remarks some conclusive comments.

\section{URBAN PLANNING FOR EMERGENCY CONDITIONS}

\subsection{Theories and laws for planning in ordinary conditions}

Planning is a decision-making process of territorial organization designed by urban planning tools defined by specific laws [19], [20]. Urban planning tools are divided into ordinary and extraordinary, for the contents they analyze and the type of constraints they impose. For instance, in Italy, according to the national law published in 1942 [8], the urban local plan 
defines the structure of a city in an ordinary condition, respecting the constraints deriving from specific laws published at different territorial levels (e.g. hydrogeological plan [25], plan for seismic prevention seismic risk prevention plan [26], [27], landscape plan [28]). Each plan is characterized by the specific issue referred to the ordinary conditions. The knowledge, the interpretation of the data, the assignment and the consequent acknowledgement of the constraints, structure a general planning process that hardly makes the plan an integrated tool. The insertion of constraints within the urban planning tool is an activity that is processed in successive phases, overlapping superordinate indications. The plan for ordinary conditions contains indirect indications for the extraordinary conditions (Fig. 2).

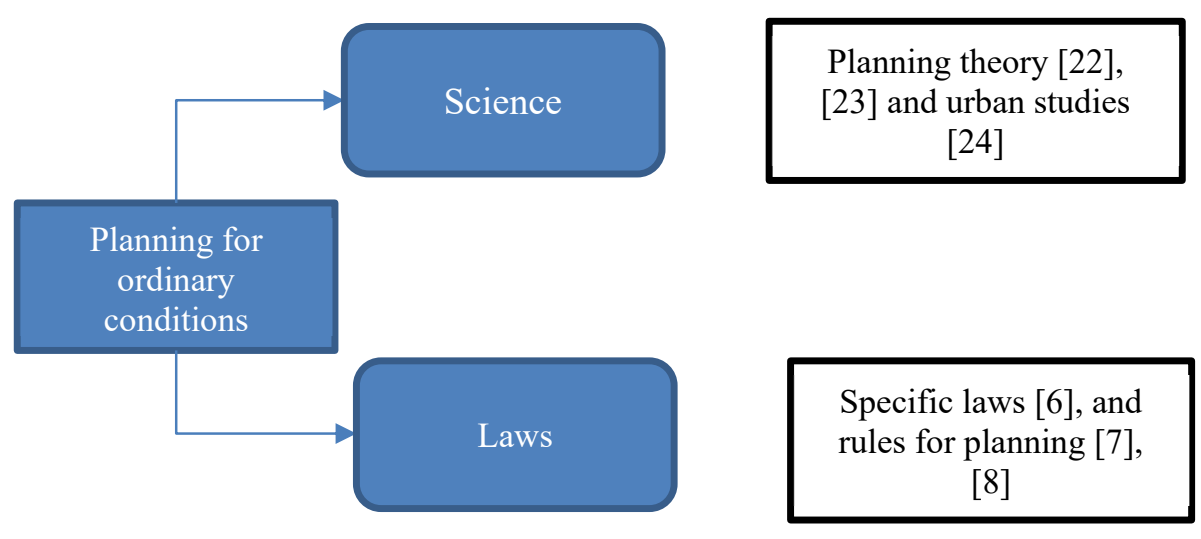

Figure 2: Planning for ordinary conditions.

As argued by Russo et al. [29], the integration of theory, rules and reality leads to the current city, defined as a smart city, a concrete expression of a system of interacting and implementing systems. For this type of city, the ordinary urban plan is inadequate, because it is based on insufficient tools for governing an inter-systemic complexity. Just as the city has adapted over the centuries, like the socio-economic processes that have characterized the different historical periods, characterizing new forms of cities, from New Towns to Smart Cities, similarly, urban planning tools, they should have made the same evolution. Planning, from a plan of regulation of fundamental norms to public life to Smart Planning to use innovative tools suitable for territorial governance, planned as an integrated smart system.

The urban plan has the task of governing the new urban complexity, proposing agile and immediate solutions for solving problems and mitigating risks. The strategic plan integrates rules and is a necessity of smart territory. It is a change of paradigm, the quantitative standards for ordinary conditions, give way to the implementation plan, based on integrated planning for ordinary and extraordinary conditions. Smart planning takes on this role as an integrated process; the scientific approach directs the design of an interconnected system, based on a holistic plan of priority actions and rigorous rules [30]. 


\subsection{Theories and laws for planning in extraordinary conditions}

Planning for extraordinary conditions regards decisions for defining activities aimed to reduce risk and its components (occurrence, vulnerability, exposure). These constitute the contents of:

- the safety science's sector that studies the asset of a territory during an emergency;

- the legislation and regulations that define urban development and land use management are finalised to prevent, protect and recovery community and environment.

Emergency planning aims to create safe, sustainable and resilient communities that can avoid or minimise the effects of emergencies and, at the same time, the ability to recover quickly and restore their socioeconomic vitality after an emergency event.

As far as concerns science, it is possible to recall planning theories and urban studies aimed to increase knowledge about emergencies. In the last twenty years, extraordinary events (from the 9/11 terrorist attack to pandemic related to COVID-19) generated disruptions in ordinary situations of territory producing different implications and new issues for research. New theoretical paradigms are needed to face extraordinary events. There are contributions from different disciplines that investigate emergency conditions from different scientific perspectives. Although many issues and functions are understudied, the knowledge base is increasing [31]. For instance, by focusing on mobility in emergency conditions, many scientific works concern the structure of transport planning [32] and the methods and models for supporting decisions in evacuation conditions.

The rules and laws are also adapting to new emergent issues and disruptions. For instance, at the global level, countries introduced new protocols to face pandemics related to COVID19 [33]. Emergency planning needs responses from regulations and laws.

\section{THE EVACUATION PLANNING FRAMEWORK}

According to the general objectives of the research, this section presents the proposed framework to integrate planning for ordinary and extraordinary conditions (Section 3.1). To reach the integration, the smart city planning model is adopted. The two conditions are considered as two layers of a smart city that are connected for reaching a convergence among theories, rules and implementations. According to the specific objective of this paper, this section presents the proposed evacuation planning framework (Section 3.2). The integrated planning approach contributes to reducing risk, increasing the knowledge of exposure's component and, in particular, the phenomenon of the mobility in evacuation conditions; knowledge is translated into an evacuation plan that is experimented with exercises aimed to increase emergency's preparedness.

\subsection{The proposed framework for planning}

The smart city, as a set of integrated infrastructures and services that increase sustainability, can be a reference model for emergency planning and management.

In a smart city, social capital, citizen, operators and decision-makers use available resources to improve quality of life. Smart city's pillars like transport, Information and Communication Technologies (ICTs) are useful tools to understand community needs in ordinary and extraordinary conditions. The tools combination constitutes the equipment of a city control room for providing an overview of all activities in the city in ordinary and in extraordinary conditions. The collected data, information and quantitative simulation 
models are useful tools for planning, managing and monitoring infrastructures and optimal services [34].

Nevertheless, tools alone are not enough. A good capacity for planning and management is needed. Smart city planning use collected data and results of analyses to support decisionmaking processes. The city government authorities can analyze the data to prevent or to face future disasters. In this context, one of the main challenges for disaster risk management regards the use of spatial and temporal data deriving from technologies (e.g. weather and traffic conditions, the integrity of infrastructures, presence of people, etc.). Adaptation of decisions against disasters effects increases the efficiency and effectiveness of operators and decision-makers [33].

A smart urban planning model is needed to support collective actions relative to face natural and manmade disasters. Some applications are available in the literature. For instance, Hartama et al. [35] proposed a mobile-GIS platform that provides a real-time platform for spatial risk's visualization. The knowledge of available resources allows to planners in the definition of the evacuation routes to safe areas. A dynamic Decision Support System (DSS) transmits data to the population to mitigate risks, and to increase the resilience against the dangers of natural disasters [36]. Smart urban planning favorites the collaboration among agencies involved in the planning process, for example through integration, and sharing of information about space environment pre and post disasters.

For instance, the study proposed by Ullah et al. [37] identifies a multilayered TechnologyOrganisation-Environment (TOE-based) risk management framework for sustainable smart city governance and in particular for risk management. A set of risks are identified and grouped into TOE categories. The knowledge of risks and their categorization contribute to the smart city government that integrate the decision-making processes about environment, governance and risks.

Wang et al. [38] represents risk management as an iterative process constituted by five key steps ("identification, analysis, evaluation, treatment and monitoring and control of risks").

Following the smart city approach proposed by the authors of this paper themselves, to plan and manage the smart city in ordinary and extraordinary conditions, it is necessary to achieve a convergence between theory, rules and implementation (Fig. 3).

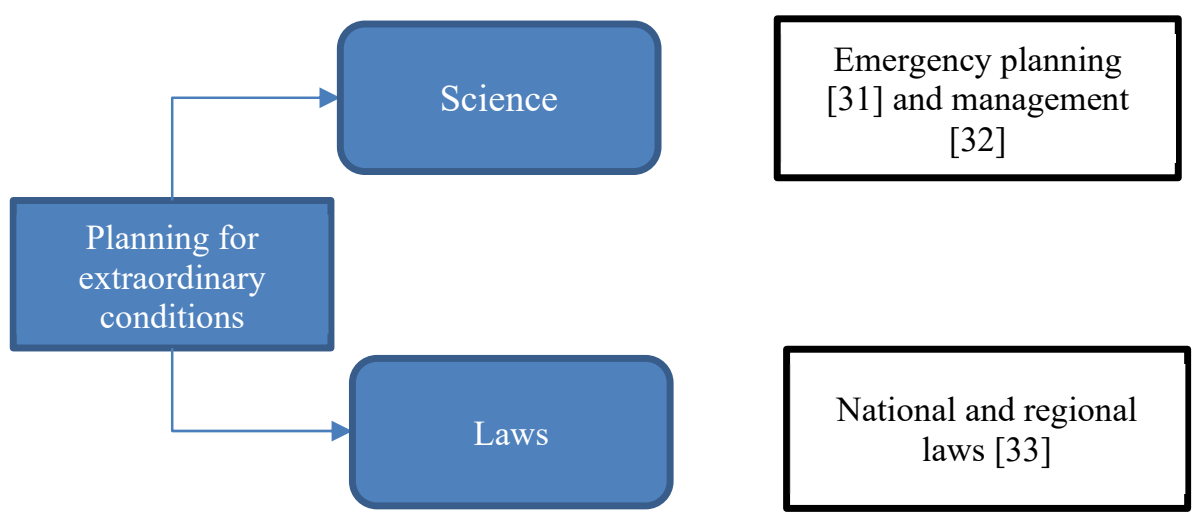

Figure 3: Planning for extraordinary conditions. 


\subsection{The specific framework for evacuation planning}

In the context of the disaster management cycle, planning is the core of the preparedness activities. Emergency preparedness is a continuous process for prioritizing actions, resource allocation for risk reduction. World Health Organization (WHO) defines emergency preparedness as "the knowledge and capacities and organizational systems developed by governments, response and recovery organizations, communities and individuals to effectively anticipate, respond to, and recover from the impacts of likely, imminent, emerging, or current emergencies". Planning constitutes the core of preparedness because it identifies, "at various levels, responsibility for a range of activities aimed at meeting specific objectives" [39].

By focusing on the problem of mobility in extraordinary conditions, and following a smart city approach (Fig. 4), it is necessary to reach a convergence among theories, rules and implementation to reduce exposure's risk component. With this aim, this paper proposes a methodology constituted by a circular process including:

- planning, that defines objectives and actions;

- training, in which, based on the results of the planning, the subjects and operators involved are trained;

- exercises, in which the planned actions are tested and the level of preparation of the operators, the subjects involved and the population is assessed;

- improvement, in which, based on the results of the previous phases, corrective actions are defined for risk reduction.
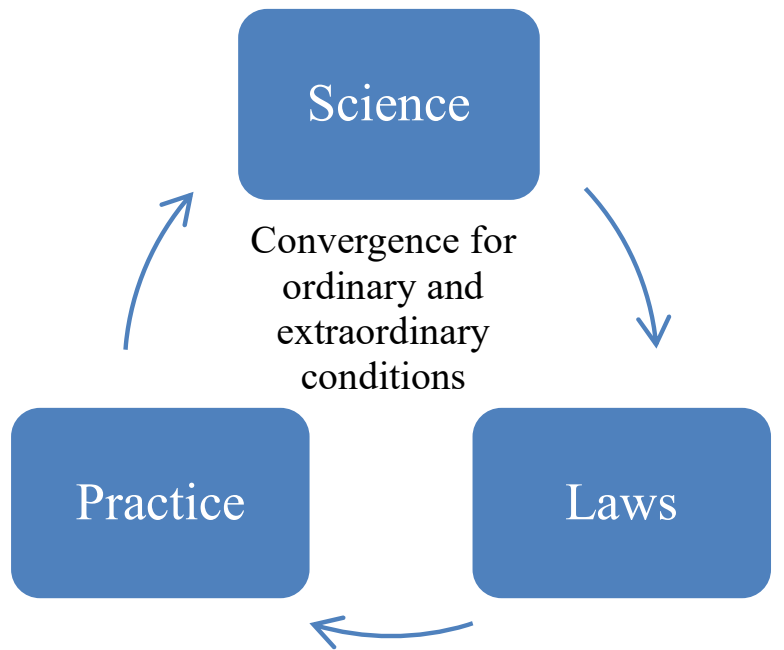

Figure 4: Integrated planning for ordinary and extraordinary condition. (Source: Adapted from Russo et al. [29].)

The proposed framework follows a circular process and it is supported by quantitative methods for simulation and monitoring of planned and implemented actions. The methodology allows to planners to define and control their decisions by means ex ante and 
ex post evaluations (Fig. 5). In the framework, TSMs play a central role because allow the analyst to simulate mobility in ordinary [41], [42] and evacuation conditions [43], [44] for supporting decisions road network setting [45], [46]. TSM fed Decision Support Systems (DSSs) [47], [48] constituting for the final goal is to produce a risk reduction [48] concerning each planned action [49] and then to increase response capacity and more in general the resilience [50].

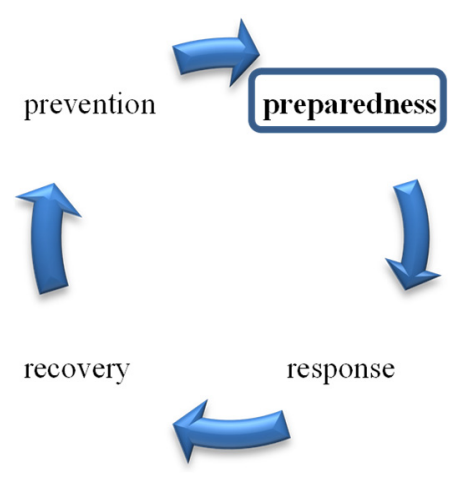

(a)

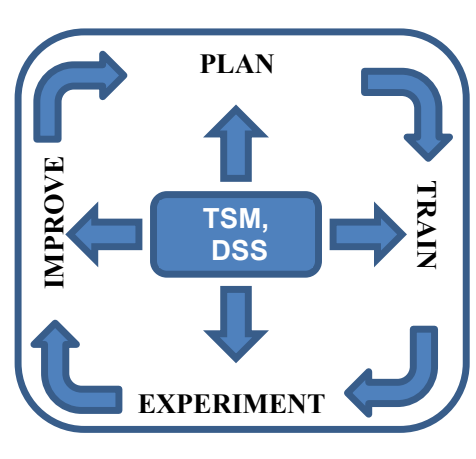

(b)

Figure 5: General planning activities. (a) Disaster management cycle; and (b) Specification of preparedness activities.

\section{EMERGENCY URBAN PLANNING IN ITALY}

\subsection{The emergency planning process}

Italy has introduced national and regional laws on Civil Protection [51]. The laws constitute the principal national reference [52]. The Italian laws define:

- the types of events and relative competencies ("type a", "type b", "type c");

- in relation to type of event, the activities and task of civil protection (prevision, prevention, rescue, recovery);

- the components of the national service of civil protection (national, regional and local public administration, group of volunteers).

Prevention activities include alerting, emergency planning, training, dissemination of knowledge of civil protection as well as information to the population and the application of technical regulations, where necessary, and exercise activities. In the following the focus is on the planning activities. The Italian Law [53] imposed the obligation to coordinate the plans and programs for the management, protection and rehabilitation of the territories with the emergency civil protection plans, adopted at different territorial scales and in particular: at national scale, the prevention and rescue programs for reducing various risk hypotheses, with specific emergency measures; at regional scale, the regional prevention and protection programs, for following the national indications; at local scale, the provincial prevention programs, for following the national and regional programs, the Prefect's plan to deal with the emergency throughout the province, the Municipal Emergency Plan (PEC), or inter- 
municipal plan, for following the criteria and procedures set out in the operational guidelines adopted by the National Department of Civil Protection and by the regional councils.

In July 2021 the Italian Government published guidelines for producing the Civil Protection Territorial Plans [27]. The guidelines implement the "Codice della protezione civile" (Code) that introduced the necessity to regulate the modalities of organization and development of the civil protection planning ("monitoring, updating and evaluation"). The aim is to guarantee a coordinated framework at the national level for integrating civil protection systems at all territorial levels, respecting at the same time the autonomy of the Regions. The specific objective is to uniform the planning methodology at different territorial levels for the management of the activities connected to the calamitous events. The code establishes that territorial planning levels are: national, regional, sub-regional (provincial/Città Metropolitana; optimal territorial and organizational scope); local (towns).

As far as concerns the evacuation planning at the local level, it is important to underline the Code promotes the external planning integration: among near towns with the introduction of the "ambit plans"; inside the same local administration (urban planning, transport, technical sectors, ...) with the coordination of the civil protection local service. Guidelines indicate the minimal strategical elements that represent the uniform contents of the emergency plans at different territorial levels, concerning:

- the uniform representation of territorial data with the "national catalogue of civil protection plans";

- the description of the organization of civil protection structures for ordinary and extraordinary conditions, to integrate planning and management;

- the territorial context of the occurrence territorial contexts;

- the individuation of the Coordination centres.

The local administrations have to define the safe areas and the routes for reaching them in the case of a tsunami. A specific focus of the guidelines is on the exercises. In particular, the guidelines introduce a classification of the exercises in relation to:

- a spatial criterion, comprehending:

- international exercises involving national and international emergency organisations;

- national exercises involving national service of civil protection aimed to test national plans for emergency conditions;

- regional, local and scope exercises involving regions, provinces, metropolitan and town administrations.

- a modality of execution criterion, comprehending:

- Command post exercise - CPX, for testing operative centres and their capacity of interrelations;

- Field exercise - FX, for testing specific operative modules in real contexts;

- Full-scale exercise - FSX, for testing (prevention, alerting, management) a planned scenario involving operative modules and population;

- Table top (TTX) for testing emergency plans and in particular specific scenarios in an artificial environment;

- Discussion-based exercise (DBX) for discussing and comparing hypothetic risk's scenarios.

Note that the guidelines do not report operative indications for network design, simulation tools of the transport system in emergency conditions. 


\subsection{The process at the local level}

The final goal of the PEC is to increase safety and security in emergency conditions. To this end, the PEC defines the operational procedures to be implemented when an emergency event occurs. Starting from the analysis of the current asset of the territory and of the potential risk scenarios, the PEC must report the indications about the procedures (e.g. assistance to the population) and the monitoring activities in case of an emergency event. This has three parts:

- general that contains information about physical and socioeconomics characteristics of the territory;

- $\quad$ lanning that indicates objectives to pursue employing, civil protection's responses for each emergency and the involved operators and their roles;

- intervention model that assigns responsibilities to the command and control levels, uses resources rationally, defines a communication system that allows a constant exchange of information.

Table 1 reports the quantity of emergency local plans adopted at urban level in Italy. Note that the national coverage rate (\% coverage) is high. Nevertheless, a great part of these plans has to be updated according to recent guidelines [27]. However, adopting a plan alone does not represent a high level of preparedness. For instance, at EU level, the lack of standardization in current disaster training methods, represent a gap in the command, control, and communication levels [54].

Table 1: Coverage of emergency local plan at the urban level in Italy [54].

\begin{tabular}{lccc}
\hline Regions/Autonomous provinces & $\begin{array}{c}\text { Total towns } \\
\text { (a) }\end{array}$ & $\begin{array}{c}\text { Total town } \\
\text { with a plan } \\
\text { (b) }\end{array}$ & $\begin{array}{c}\text { \% coverage } \\
(\mathrm{a}) /(\mathrm{b})\end{array}$ \\
\hline Abruzzo & 305 & 301 & $99 \%$ \\
Basilicata & 131 & 123 & $94 \%$ \\
Calabria & 409 & 391 & $96 \%$ \\
Campania & 550 & 486 & $88 \%$ \\
Emilia-Romagna & 334 & 322 & $96 \%$ \\
Friuli Venezia Giulia & 216 & 216 & $100 \%$ \\
Lazio & 378 & 366 & $97 \%$ \\
Liguria & 235 & 220 & $94 \%$ \\
Lombardia & 1,544 & 1,209 & $78 \%$ \\
Marche & 239 & 239 & $100 \%$ \\
Molise & 136 & 136 & $100 \%$ \\
Piemonte & 1,206 & 1,119 & $93 \%$ \\
Puglia & 258 & 256 & $99 \%$ \\
Sardegna & 377 & 297 & $79 \%$ \\
Sicilia & 390 & 190 & $49 \%$ \\
Toscana & 276 & 250 & $91 \%$ \\
Trentino AA - Bolzano (aut. prov.) & 116 & 85 & $73 \%$ \\
Trentino AA - Provincia Trento (aut. prov) & 210 & 210 & $100 \%$ \\
Valle d'Aosta & 74 & 74 & $100 \%$ \\
Veneto & 575 & 527 & $92 \%$ \\
\hline Total & 8,051 & 7,108 & $88 \%$ \\
\hline
\end{tabular}




\section{CONCLUSIVE REMARKS}

This paper has investigated the possibility to integrate planning for ordinary and extraordinary conditions. From the analysis of the literature review, it emerges a separation between planning approaches for ordinary and extraordinary conditions. The separation also concerns science that produces theories and laws for urban planning. This paper proposes a smart city planning approach to reach a convergence among theories, rules and implementation to integrate urban planning for ordinary and extraordinary conditions. In particular, the focus of this paper is on evacuation planning and a framework that integrates planning, training, experimentation and evaluation for improvement. The specific Italian case study shows a partial application of the proposed framework. The analysis of national and regional guidelines shows a set of limits, respect to the proposed framework. More integration between science and rules is needed. The exercises proposed by Italian guidelines could produce a great quantity of data and information useful to support the construction of transport system models available in the literature. This implies the necessity to introduce an integrated planning process for ordinary and extraordinary conditions. Further developments of this research concern the possibility to integrate TSM and ICT in an ITS for supporting integrated planning and decision-makers. These tools can be part of a control room in a smart city.

[1] Bullock, J., Haddow, G. \& Coppola, D.P., Introduction to Emergency Management 6th ed., Elsevier, 2017.

[2] UN, United Nations Sendai Framework for Disaster Risk Reduction 2015-2030. https://www.unisdr.org/files/43291_sendaiframeworkfordrren.pdf. Accessed on: 3 Oct. 2021.

[3] EU, European Union Civil Protection Mechanism (EUCPM). https://ec.europa.eu/ echo/what/civil-protection/mechanism_en. Accessed on: 3 Oct. 2021.

[4] Joss, S., Sengers, F., Schraven, D., Caprotti, F. \& Dayot, Y., The smart city as global discourse: Storylines and critical junctures across 27 cities. J. Urban Technol., 26, pp. 3-34, 2019.

[5] Fazzio, F., Olivieri, M., Parotto, R. \& Pizzo, B., Linee guida per la definizione della Struttura Urbana Minima nel PRG. Ricerca Por-Fesr 2007-2013, Regione Umbria, Direzione Ambiente, Territorio e Infrastrutture. Dipartimento di Pianificazione Territoriale e Urbanistica, Università di Roma La Sapienza, 2010.

[6] French Government, Law on expropriation of 26 March, 1852. https://www.legifrance.gouv.fr. Accessed on: 3 Oct. 2021.

[7] UK Government, Law of 9 August 1844 for London and around, 1844. www.parliament.uk. Accessed on: 3 Oct. 2021.

[8] Italian Law n. 1150 of 17 August 1942, Legge Urbanistica.

[9] Taylor, N., Urban Planning Theory Since 1945. SAGE: London, 1998.

[10] Italian Law, n. 1444 of 1968, Standard Urbanistici.

[11] Musolino, G. \& Panuccio, P., Planning instruments in Italy and the UK: Private and public spaces for emergency events in urban areas. WIT Transactions on The Built Environment, vol. 134, WIT Press: Southampton and Boston, 2013.

[12] Cirianni, F., Panuccio, P. \& Rindone, C., A comparison of urban planning systems between the UK and Italy: Commercial development and city logistic plan. WIT Transactions on The Built Environment, vol. 130, WIT Press: Southampton and Boston, pp. 785-797, 2013. 
[13] Di Salvo, G., Giuffré, M., Pellegrino, P. \& Pizzo, B., Rischio sismico e pianificazione: dall'emergenza all'ordinario. La struttura urbana minima come pretesto per ripensare la città pubblica, INU - Biennale dello spazio pubblico, Dipartimento Design Tecnologia dell'Architettura Territorio e Ambiente, Università di Roma La Sapienza, 2011.

[14] Sarlo, A. (ed.), Mitigazione del rischio sismico in aree urbane. Un'esperienza su Reggio Calabria, Iiriti Editore: Reggio Calabria, Italy, 2004.

[15] Fera, G., La città antisismica; storia, metodologie, prospettive, Gangemi Editore: Reggio Calabria, Italy, 1990.

[16] Hall, P.G., Urban and Regional Planning, 4th ed., Routledge: London, 2002.

[17] Forester, J., Critical Theory and Public Life, MIT Press: Cambridge, 1985.

[18] Vitetta, A., Risk reduction in transport system in emergency conditions: A framework for network design problem. WIT Transactions on the Built Environment, vol. 206, WIT Press: Southampton and Boston, submitted for publication, 2021.

[19] Russo, F. \& Chilà, G., Risk reduction in transport system in emergency conditions: A framework for demand analysis. WIT Transactions on the Built Environment, vol. 206, WIT Press: Southampton and Boston, submitted for publication, 2021.

[20] Musolino, G., Risk reduction in transport system in emergency conditions: A framework for supply analysis. WIT Transactions on the Built Environment, vol. 206, WIT Press: Southampton and Boston, submitted for publication, 2021.

[21] Di Gangi, M. \& Belcore, O.M., Risk reduction in transport system in emergency conditions: a framework for decision support systems. WIT Transactions on the Built Environment, vol. 206, WIT Press: Southampton and Boston, submitted for publication, 2021.

[22] Friedmann, J., Planning theory revisited. European Planning Studies, 6(3), pp. 245253, 1998. DOI:10. 1080/09654319808720459.

[23] Faludi, A., Planning Theory, Pergamon Press: Oxford, 1973.

[24] Allmendinger, P., Planning Theory, 2nd ed., Palgrave Macmillan: Basingstoke, 2009.

[25] Italian Law n. 183 of 1989, Piano Assetto Idrogeologico.

[26] Italian Law n. 24 of 2020, Classificazione del rischio sismico delle costruzioni.

[27] Italian directive of President of the Council of Ministers 30 April 2021. Indirizzi per la predisposizione dei piani di protezione civile ai diversi livelli territoriali. Official Gazettes n. 160 of 6 July 2021.

[28] Italian Law n. 42 of 2004, Codice dei Beni Culturali e del Paesaggio.

[29] Russo, F., Panuccio, P. \& Rindone, C., European plans for the smart city: from theories and rules to logistics test case. European Planning Studies, 2016.

DOI: $10.1080 / 09654313.2016 .1182120$.

[30] Panuccio, P., Smart planning: From city to territorial system. Sustainability, 11, p. 7184, 2019. DOI: 10.3390/su11247184.

[31] McEntire, D.A., The status of emergency management theory: Issues, barriers, and recommendations for improved scholarship. Paper Presented at the FEMA Higher Education Conference, June 8, Emmitsburg, MD, 2004.

[32] Russo, F. \& Rindone, C., The planning process and logical framework approach in road evacuation: A coherent vision. WIT Transactions on The Built Environment, vol. 117, WIT Press: Southampton and Boston, pp. 415-425, 2011.

[33] Gkiotsalitis, K. \& Cats, O., Public transport planning adaptation under the COVID-19 pandemic crisis: Literature review of research needs and directions. Transp. Rev., 41, pp. 374-392, 2021. 
[34] Russo, F., Panuccio, P. \& Rindone, C., The process of smart city definition at an EU level. WIT Transactions on Ecology and the Environment, vol. 191, WIT Press: Southampton and Boston, pp. 979-989, 2014.

[35] Hartama, D. et al., The planning of smart city to mitigate the impacts of natural disaster in North Sumatra. 1st International Conference on Information Technology in Disaster Risk Reduction (ITDRR), Sofia, Bulgaria, pp. 147-154, 2016.

DOI: 10.1007/978-3-319-68486-4_12. hal-03213128.

[36] Yamashita, S., Watanabe, R. \& Shimatani, Y., Smart adaptation activities and measures against urban flood disasters. Sustainable Cities and Society, 27, pp. 175184, 2016.

[37] Ullah, F., Qayyum, S., Thaheem, M.J., Al-Turjman, F. \& Sepasgozar, S.M.E., Risk management in sustainable smart cities governance: A TOE framework. Technological Forecasting and Social Change, 167, 2021.

[38] Wang, J., Lin, W. \& Huang, Y.H., A performance-oriented risk management framework for innovative R\&D projects. Technovation, 30, pp. 601-611, 2010. DOI: 10.1016/j.technovation.2010.07.003.

[39] World Health Organization (WHO), A strategic framework for emergency preparedness. World Health Organization: Geneva, 2017. Licence: CC BY-NC-SA 3.0 IGO.

[40] Russo, F. \& Chilà, G., Dynamic approaches to demand model in evacuation conditions. WIT Transactions on The Built Environment, vol. 111, WIT Press: Southampton and Boston, pp. 303-312, 2010.

[41] Russo, F. \& Chilà, G., Safety of users in road evacuation: Modelling and DSS for demand. WIT Transactions on Ecology and the Environment, vol. 120, WIT Press: Southampton and Boston, pp. 465-474, 2009.

[42] Marcianò, F.A., Musolino, G. \& Vitetta, A., A system of models for signal setting design of a signalized road network in evacuation conditions. WIT Transactions on the Built Environment, vol. 111, WIT Press: Southampton and Boston, pp. 313-323, 2010.

[43] Marcianò, F.A., Musolino, G. \& Vitetta, A., Within-day traffic assignment and signal setting in road evacuation: A procedure with explicit path enumeration. WIT Transactions on the Built Environment, vol. 117, WIT Press: Southampton and Boston, pp. 403-414, 2011.

[44] Marcianò, F.A, Musolino, G. \& Vitetta A., Signal setting design on a road network: Application of a system of models in evacuation conditions. WIT Transactions on Information and Communication Technologies, vol. 43, WIT Press: Southampton and Boston, pp. I443-I454, 2010.

[45] Marcianò F.A, Musolino G. \& Vitetta A., Signal setting optimization on urban road transport networks: The case of emergency evacuation. Safety Science, 72, pp. 209220, 2015.

[46] Di Gangi, M., Watling, D. \& Di Salvo, R., Modeling evacuation risk using a stochastic process formulation of mesoscopic dynamic network loading. IEEE Transactions on Intelligent Transportation Systems, 2020. DOI: 10.1109/TITS.2020.3038478.

[47] Di Gangi, M. \& Polimeni, A., A mesoscopic approach to model route choice in emergency conditions. Paper presented at the Springer Proceedings in Mathematics and Statistics, 217, pp. 547-555, 2017. DOI: 10.1007/978-3-319-67308-0_55.

[48] Russo, F. \& Vitetta, A., Safety of users in road evacuation: General methodology and main results. WIT Transactions on the Built Environment, vol. 96, WIT Press: Southampton and Boston, pp. 763-772, 2007. 
[49] Russo, F. \& Rindone, C., Urban exposure: Training activities and risk reduction. WIT Transactions on Ecology and the Environment, vol. 191, WIT Press: Southampton and Boston, pp. 991-1001, 2014.

[50] Russo, F., Rindone, C. \& Trecozzi, M.R., The role of training in evacuation. WIT Transactions on Information and Communication Technologies, vol. 44, WIT Press: Southampton and Boston, pp. 491-502, 2012.

[51] Italian Law n. 225 of 24 February 1992, Istituzione del Servizio nazionale della protezione civile.

[52] Italian Law 2012 n. 59, Disposizioni urgenti per il riordino della protezione civile.

[53] Italian Law 12 July 2012 n. 100, Conversione in legge, con modificazioni, del decretolegge 15 maggio 2012, n. 59, recante disposizioni urgenti per il riordino della protezione civile.

[54] Khorram-Manesh, A. et al., Education in disaster management and emergencies: Defining a new European course. Disaster Medicine and Public Health Preparedness, 9(3), pp. 245-255, 2015.

[55] Italian Department for Civil Protection Mappa dei piani di protezione civile comunali dati di dettaglio, 2020. https://servizio-nazionale.protezionecivile.gov.it/it/attivita/ prevenzione/pianificazione-di-protezione-civile/mappa-piani-di-protezione-civile. Accessed on: 3 Oct. 2021. 